Research article

Open Access

\title{
A monoclonal antibody against kininogen reduces inflammation in the HLA-B27 transgenic rat
}

\author{
James C Keith Jr' ${ }^{1}$, Irma M Sainz ${ }^{2}$, Irma Isordia-Salas ${ }^{2}$, Robin A Pixley², Yelena Leathurby ${ }^{1}$, \\ Leo M Albert ${ }^{1}$ and Robert W Colman²
}

\author{
1Department of Cardiovascular and Metabolic Diseases Research, Wyeth Research, Cambridge, Massachusetts, USA \\ ${ }^{2}$ The Sol Sherry Thrombosis Research Center, Temple University School of Medicine, Philadelphia, Pennsylania, USA \\ Corresponding author: Robert W Colman, colmanr@temple.edu \\ Received: 31 Jan 2005 Accepted: 3 Mar 2005 Published: 4 Apr 2005 \\ Arthritis Research \& Therapy 2005, 7:R769-R776 (DOI 10.1186/ar1728) \\ This article is online at: http://arthritis-research.com/content/7/4/R769 \\ (c) 2005 Keith et al.; licensee BioMed Central Ltd. \\ This is an Open Access article distributed under the terms of the Creative Commons Attribution License (http://creativecommons.org/licenses/by/ \\ 2.0), which permits unrestricted use, distribution, and reproduction in any medium, provided the original work is properly cited.
}

\begin{abstract}
The human leukocyte antigen B27 (HLA-B27) transgenic rat is a model of human inflammatory bowel disease, rheumatoid arthritis and psoriasis. Studies of chronic inflammation in other rat models have demonstrated activation of the kallikrein-kinin system as well as modulation by a plasma kallikrein inhibitor initiated before the onset of clinicopathologic changes or a deficiency in high-molecular-mass kininogen. Here we study the effects of monoclonal antibody $\mathrm{C} 11 \mathrm{C} 1$, an antibody against high-molecular-mass kininogen that inhibits the binding of highmolecular-mass kininogen to leukocytes and endothelial cells in the HLA-B27 rat, which was administered after the onset of the inflammatory changes. Thrice-weekly intraperitoneal injections of monoclonal antibody $\mathrm{C} 11 \mathrm{C} 1$ or isotype $\operatorname{lgG}_{1}$ were given to male 23-week-old rats for 16 days. Stool character as a measure of intestinal inflammation, and the rear limbs for clinical
\end{abstract}

signs of arthritis (tarsal joint swelling and erythema) were scored daily. The animals were killed and the histology sections were assigned a numerical score for colonic inflammation, synovitis, and cartilage damage. Administration of monoclonal $\mathrm{C} 11 \mathrm{C} 1$ rapidly decreased the clinical scores of pre-existing inflammatory bowel disease $(P<0.005)$ and arthritis $(P<$ $0.001)$. Histological analyses confirmed significant reductions in colonic lesions $(P=0.004)$ and synovitis $(P=0.009)$. Decreased concentrations of plasma prekallikrein and highmolecular-mass kininogen were found, providing evidence of activation of the kallikrein-kinin system. The levels of these biomarkers were reversed by monoclonal antibody $\mathrm{C} 11 \mathrm{C} 1$, which may have therapeutic potential in human inflammatory bowel disease and arthritis.

\section{Introduction}

Human leukocyte antigen B27 (HLA-B27) transgenic Fisher rats are normal at birth but develop chronic inflammation of multiple organ systems as they age. Transgenic rats of this strain, overexpressing the human HLA-B27 and $\beta_{2}$-microglobulin proteins, develop lesions of the gastrointestinal system, the joints, the skin, and the gonads, which seem similar to the spondyloarthropathies in humans that have been associated with the HLA-B27 and $\beta_{2}$-microglobulin genes [1,2]. The gastrointestinal inflammation is mostly limited to the mucosa and submucosa, exhibiting histological features similar to those present in inflammatory bowel disease (IBD) [1-4]. Chronic intestinal inflammation is the first to occur, with clinical signs of diarrhea apparent after 12 weeks of age. About 4 weeks later, joint inflammation is seen, and these rats can also be used for a model of inflammatory arthritis [3].

The plasma kallikrein-kinin system (KKS), which is initiated by factor XIla [5] or prolylcarboxypeptidase [6] after binding of high-molecular-mass kininogen (HK) and plasma prekallikrein (PK) to the surface of endothelial cells and leukocytes [7], generates the enzyme kallikrein. Kallikrein in turn cleaves HK to yield the inflammatory mediators bradykinin (BK) and cleaved high-molecular-mass kininogen ( $\mathrm{HKa})$ [8]. Kallikrein is chemotactic, aggregates neutrophils [9], stimulates superoxide formation, and releases elastase from neutrophils [10], all of

$\overline{\mathrm{BK}}=$ bradykinin; $\mathrm{H} \& \mathrm{E}=$ hematoxylin and eosin; $\mathrm{HK}=$ high-molecular-mass kininogen; HKa = cleaved high-molecular-mass kininogen; HLA-B27 = human leukocyte antigen B27; IBD = inflammatory bowel disease; KKS = kallikrein-kinin system; mAb = monoclonal antibody; PG-APS = peptidoglycan-polysaccharide polymers from group A streptococci; $\mathrm{PK}=$ prekallikrein. 


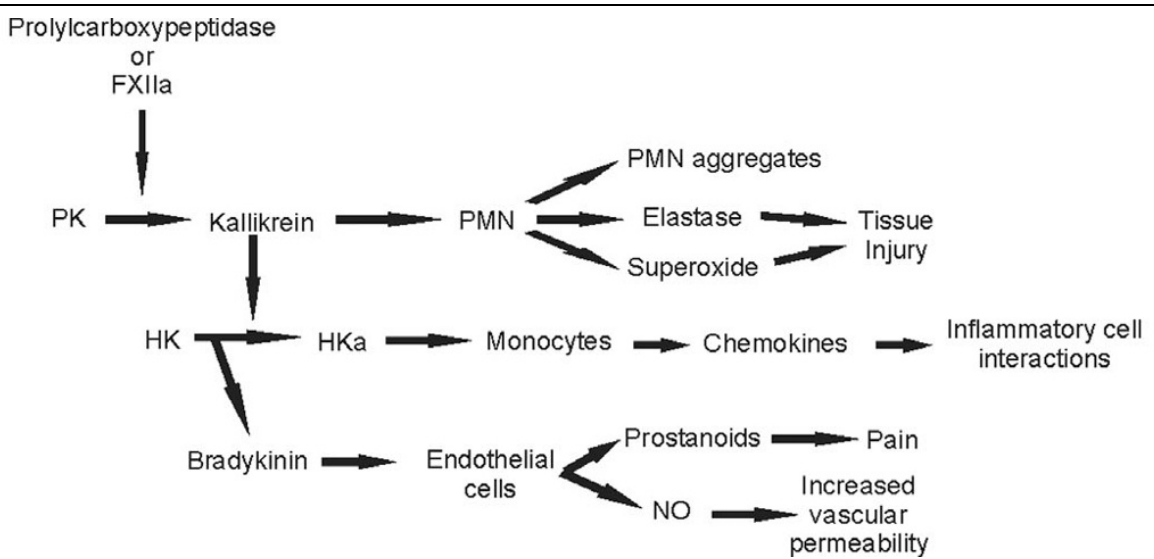

Kallikrein-kinin system (KKS). The KKS is initiated by factor Xlla (FXlla) or prolylcarboxypeptidase on the endothelial cell and leukocyte (polymorphonuclear cell (PMN)) surface, generating the enzyme kallikrein, which in turn cleaves high-molecular-mass kininogen (HK) to yield bradykinin (BK) and cleaved high-molecular-mass kininogen (HKa). Kallikrein is chemotactic, aggregates neutrophils, and stimulates the release of elastase and superoxide (potent inducers of tissue injury). BK stimulates vasodilation, mediates pain through the release of prostaglandins, and stimulates vascular permeability through the generation of nitrous oxide (NO). PK, prekallikrein.

which induce tissue injury. BK stimulates vascular permeability and angiogenesis after binding to endothelial cells [11] and also mediates pain through the release of prostanoids [12]. $\mathrm{HKa}$ stimulates cytokine release from rat [13] and human monocytes[14]. Thus, activation of the KKS is an inflammatory stimulus that might be operative in human disease, as represented in Fig. 1.

We have shown that KKS activation mediates the acute and chronic phases of $\mathrm{T}$ cell-mediated arthritis induced by peptidoglycan-polysaccharide complexes from Group A streptococci (PG-APS) in Lewis rats [15] and is selectively activated in granulomatous enterocolitis in these susceptible rats, but not in resistant Buffalo rats [16]. We have discovered a genetic difference in kininogen structure between resistant Buffalo and Fischer F344 inbred rats and the susceptible Lewis rat that results in accelerated cleavage of $\mathrm{HK}$ in the latter. This mutation consists of a single nucleotide polymorphism coding for the amino acid alteration, S511N, in the HK gene of Lewis (N511) (mutant) versus Buffalo and Fischer (S511) (wild-type) rats that results in an altered glycosylation state [17] and an increased rate of HK cleavage by plasma kallikrein with release of BK. We have shown that BK has a critical role in the PG-APS-mediated arthritis [18]. We have also implicated $\mathrm{BK}$ receptors as having a role in a different model of IBD, indomethacin-induced colitis [19]. Most recently, we have shown that a monoclonal antibody (mAb), C11C1, acting to prevent $\mathrm{HK}$ interaction with cells involved in inflammatory disorders, inhibited the development of acute and chronic arthritis in the PG-APS model [20].

To demonstrate that this effect was not specific for a single model and to allow us to assess the possibility of treating established chronic inflammation, we examined an HLA-B27 transgenic rat model of chronic inflammation of the intestine and peripheral joints. Administration of mAb C11C1 ameliorated colitis and tarsal joint inflammation.

\section{Materials and methods}

HLA-B27 transgenic male rats were purchased from Taconic Laboratories (Germantown, NY) and housed one per cage in accordance with Wyeth Research facility standard operating procedures. They received a standard regimen of food and water. Animals were thoroughly acclimated to the laboratory before the beginning of the study. The study was approved by the Wyeth Research (Cambridge) Institutional Animal Care and Use Committee.

At 23 weeks of age, 10 male rats presenting the clinical signs of colitis (diarrhea) and arthritis (erythematous and swollen hind paws) were randomized into either an isotype control mAb lgG $(n=5)$ or mAb C11C1 $(n=5)$ treatment group. Each rat was weighed daily and received an intraperitoneal injection of isotype $\operatorname{lgG}_{1}(6 \mathrm{mg} / \mathrm{kg})$ or mAb C11C1 $(1.9 \mathrm{mg} /$ $\mathrm{kg}$ ) three times per week for 16 days. Stool character observations for each animal on each day of study were assigned numerical scores of 3 for diarrhea, 2 for soft stool and 1 for normal stool. The clinical signs of arthritis in the tarsal joints were monitored daily in all of the animals. This assessment was performed visually with a scale for swelling ( 0 to 3 ) and for erythema ( 0 to 3 ) of the hindpaws (normal paw $=0$, mild $=$ 1 , moderate $=2$, severe $=3$ ). The maximum possible score for arthritis per animal per paw per day was 6 (total per animal = 12 for both hindpaws).

\section{Histological analyses}

At the end of the experiment, the animals were killed with $100 \%$ carbon dioxide, and the distal $10 \mathrm{~cm}$ of colon of each 
rat was removed and opened. Four standardized samples of colon were immersed in 10\% neutral buffered formalin [21]. Samples from each rat were prepared for histological evaluation. The formalin-fixed tissues were processed in a Tissue Tek vacuum infiltration processor, Model 4617 (Miles, Inc., West Haven, CT) for paraffin embedding. The samples were sectioned at $5 \mu \mathrm{m}$ thickness and then stained with hematoxylin and eosin (H\&E) for histological evaluation. Histological lesions were assigned scores in accordance with a previously defined scoring scheme [21-24]. In brief, the severity in the colonic sections was evaluated for ulcer size (none $=0$, small $=1$, large $=2$ ), degree of inflammation (none $=0$, mild $=1$, moderate $=2$, severe $=3$ ), depth of lesion (none $=0$, submu$\operatorname{cosa}=1$, muscularis propria $=2$, involving serosa $=3$ ), and fibrosis ( none $=0$, mild $=1$, severe $=2$ ). The total histological scores for the colon specimens ranged from 0 to 10 .

During necropsy, segments of the rear limbs (with the tarsal joints) were removed, fixed in $10 \%$ buffered formalin, and examined as described previously [22]. After decalcification, histological sections were obtained and stained with $\mathrm{H} \& \mathrm{E}$ or Safranin O/Fast Green stain. Synovial tissue from tarsal joints was evaluated on the basis of synovial hyperplasia (synovial cell proliferation: mild $=1$, moderate $=2$, villus formation $=3$ ), fibroplasia (subsynovial fibrosis: minimal $=1$, one-third to onehalf of areolar tissue replacement $=2$, whole thickness areolar tissue replacement $=3$ ), inflammatory cell infiltrates (occasional $=0$, small numbers/around blood vessels $=1$, small focal collections $=2$, large foci $=3$ ), and pannus formation (organizing inflammatory exudates within the joint space: nondetectable $=0$, detectable $=2$ ). The total histological score for synovial inflammation ranged from 0 to 11 [25]. Articular cartilage was evaluated with Mankin's histological grading system [26]: cartilage organization changes (normal $=0$, surface irregularity $=1$, pannus and surface irregularity $=2$, clefts to transitional zone $=3$, clefts to radial zone $=4$, clefts to calcified zone $=5$, complete disorganization $=6$ ), chondrocyte proliferation (none $=0$, hypercellularity $=1$, cloning $=2$, hypocellularity $=3$ ), proteoglycan contents (Safranin O/Fast Green staining, normal $=0$, slight reduction $=1$, modest reduction $=2$, severe reduction $=3$, no dye noted $=4$ ), and tidemark integrity (intact $=0$, crossed by blood vessels $=1$ ). The total Mankin score ranged from 0 to 14 . Histological H\&Estained sections taken from kidney, liver, and spleen from the $\mathrm{mAb} \mathrm{C} 11 \mathrm{C} 1$-treated group were evaluated for signs of systemic inflammation and/or toxicity.

\section{Blood collection}

Blood samples were obtained by cardiac puncture with a 19gauge, 3/4-inch needle on a $10 \mathrm{ml}$ polypropylene syringe (BD Medical Systems, Franklin Lakes, NJ). The sample was obtained from the left atrium as the heart beat. The sample of 3 to $5 \mathrm{ml}$ was obtained by slow vacuum (to prevent hemolysis) within a minute (to prevent clotting in the syringe). The blood was then transferred into pre-marked, $1 \mathrm{ml}$ Eppendorf polypro- pylene tubes (Fisher Scientific, Pittsburgh, PA) containing 100 $\mu \mathrm{l}$ of anticoagulant (citrate-phosphate-dextrose solution with adenine, Sigma C-4431; Sigma Chemical Co.) to a final volume of $1 \mathrm{ml}$ and gently mixed. Plasma was isolated by double centrifugation of the citrated blood in polypropylene tubes (Fisher Scientific) at $23^{\circ} \mathrm{C}$. Aliquots were stored at $-70^{\circ} \mathrm{C}$ until assayed.

\section{Assays of KKS activation ex vivo}

PK function levels were performed by a microtiter, amidolytic assay using a chromogenic substrate, S-2302 (Pro-Phe-Argp-nitroanilide; Chromogenix, Moindal, Sweden), as described previously [27]. HK coagulant activity was evaluated by our modification of an APTT test assay $[28,29]$, using total kininogen-deficient plasma purchased from George King (Overland Park, KS) [19]. In addition, factor XI and factor XII coagulant activity assays were performed with a similar method using the appropriate deficient plasma obtained from George King.

\section{Statistical analyses}

All the evaluations were made by examiners blinded to the treatment groups. All of the parameters were subjected to Students' $t$ test between groups. Data were expressed as means \pm SEM, and differences were deemed significant if $P<0.05$.

\section{Results}

Twenty-four hours after the onset of therapy in the $m A b$ C11C1-treated rats, the clinical signs of intestinal inflammation (diarrhea) had disappeared, and the stool character remained normal or nearly normal for the duration of the experiment (Fig. 2a). Histological analysis demonstrated significant reductions (from 60 to $75 \%$ ) in lesion scores in the animals treated with $\mathrm{mAb} \mathrm{C} 11 \mathrm{C} 1$ in comparison with animals injected with isotype $\lg _{1}$ (Fig. 2b,c).

Daily visual inspection of the tarsal joints in the mAb C11C1treated animals revealed marked reductions in the degree of swelling and erythema of the joints compared with isotypetreated animals. As can be seen in Fig. 3a, within 24 hours of the onset of therapy, the mean joint histological scores in the mAb C11C1-treated rats decreased by about $50 \%$ compared with the mAb control group. By the end of 1 week of treatment, the clinical signs of arthritis had almost disappeared. Evaluation of the histological features of the arthritis in the tarsal joints at the termination of the experiment on day 16 showed a marked reduction in the parameters of synovitis in the rats treated with $\mathrm{mAb} \mathrm{C} 11 \mathrm{C} 1$ compared with those receiving isotype $\operatorname{lgG}_{1}(P<0.05)$ (Fig. 3b,c). In a similar manner to the changes seen in the colon, 40 to $60 \%$ decreases in the various components of the synovitis score occurred. However, the effects on the articular cartilage were more modest. Nevertheless, the cartilage organization, chondrocyte proliferation and total Mankin score were significantly decreased (Fig. 3d). Tidemark integrity was preserved in all groups (data not shown). Histological analysis of kidney, liver and spleen 
Figure 2

(a)

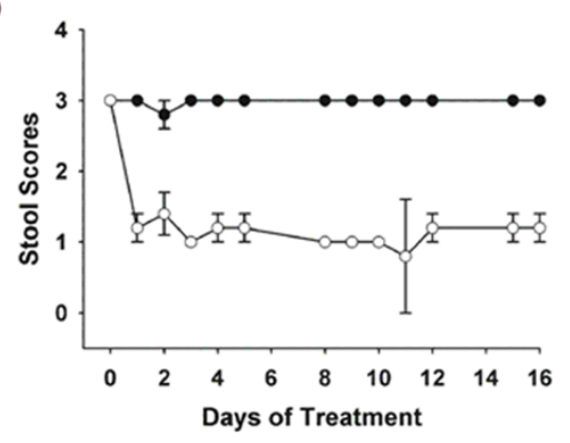

(b)
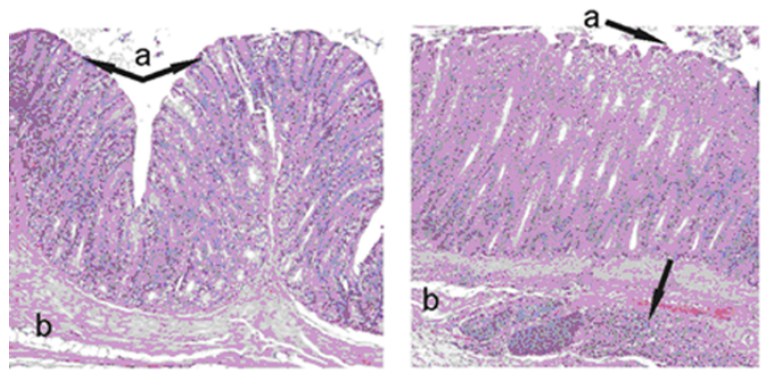

(c)

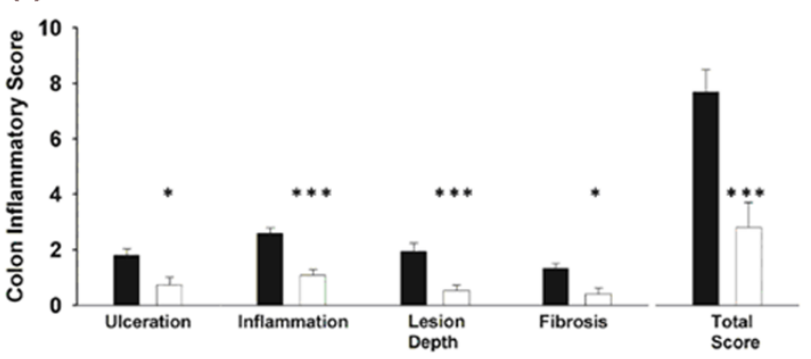

Effect of mAb C11C1 on HLA-B27 transgenic rats colonic inflammation. (a) Effects of monoclonal antibody (mAb) $\mathrm{C} 11 \mathrm{C} 1$ on diarrhea in human leukocyte antigen B27 (HLA-B27) rats. Stool score was determined five times a week (normal stool $=1$, soft stool $=2$, watery stool $=$ 3). $\mathrm{mAb} C 11 \mathrm{C} 1(1.9 \mathrm{mg} / \mathrm{kg})$ was administered three times a week for 16 days. The control group received murine isotype $\lg G_{1}(6 \mathrm{mg} / \mathrm{kg})$ three times a week for 16 days. All stool scores are significantly different between the two groups for each corresponding day $(P<0.005)$ except for day $11(P=0.03)$. Data are shown as means \pm SEM. Filled circles, IgG 1 -treated group; open circles, $\mathrm{mAb} \mathrm{C} 11 \mathrm{C} 1$-treated group. (b) Effects of mAb C11C1 on colonic mucosa in HLA-B27 rats. Photomicrographs of representative sections of colon from $\mathrm{C} 11 \mathrm{C} 1$-treated (left) and lgG-treated (right) HLA-B27 transgenic rats. Note the extensive inflammatory cell infiltrates within the mucosa (a) and submucosa (b) with loss of villus formation on the mucosal surface indicated by the arrow (a) in the lgG group (right) compared with the C11C1 group (left). The branched arrow (left) points to the villus formation normally present in the colon (mAb C11C1-treated group). Hematoxylin and eosin stain; original magnification $\times 100$. (c) Effects of mAb C11C1 on colonic inflammatory changes in HLA-B27 rats. mAb C11C1 decreased inflammatory changes in the colonic sections as evaluated by ulceration $(P=0.02)$, inflammation $(P<0.001)$, depth of lesion $(P=$ $0.004)$, and degree of fibrosis replacement $(P=0.01)$ compared with $\operatorname{lgG}_{1}$ administration. Treatment with $\mathrm{mAb} \mathrm{C} 11 \mathrm{C} 1$ (open bars) significantly decreased the extent and intensity of the total colonic inflammatory score $(P=0.004)$. Data are shown as means \pm SEM. ${ }^{\star} P<0.05$; ${ }^{\star * \star} P<0.005$.
Figure 3
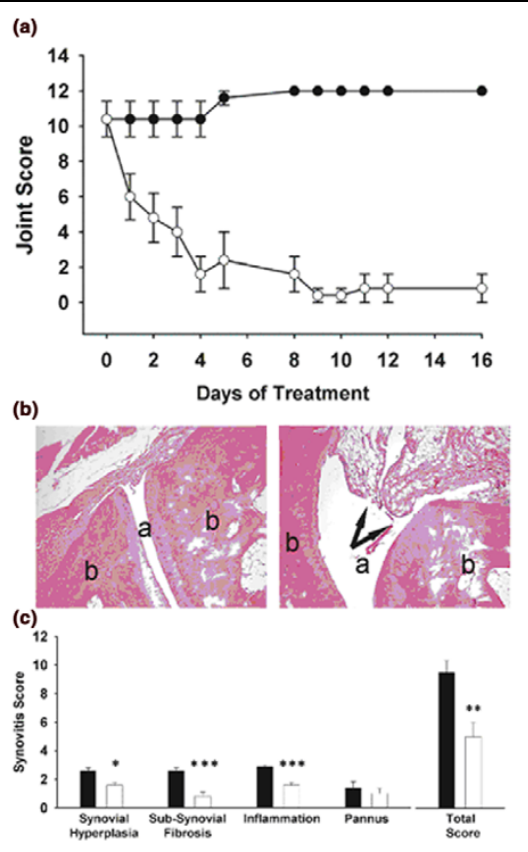

(d)

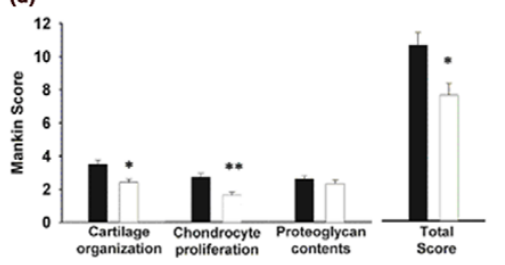

Effect of mAb C11C1 on HLA-B27 transgenic rat inflammatory arthritis. (a) Effects of monoclonal antibody (mAb) $\mathrm{C} 11 \mathrm{C} 1$ on clinical signs of arthritis in human leukocyte antigen B27 (HLA-B27) rats. mAb C11C1 was administered at the same dose and frequency as in Fig. 2a. Mean joint score was determined daily, except at weekends. All joint scores are significantly different between the two groups for each corresponding day $(P<0.001)$ except for days $1(P>0.03), 2(P=0.01)$ and $3(P$ $=0.006)$. Data are shown as means \pm SEM. Filled circles, IgG1-treated group; open circles, mAb C11C1-treated group. (b) Effects of mAb $\mathrm{C} 11 \mathrm{C} 1$ on joint histology in HLA-B27 rats. Photomicrographs of representative sections of tarsal joints from C11C1-treated (left) and lgGtreated (right) HLA-B27 transgenic rats. Note the clear joint space (a) and normal appearance of bone (b) in the $\mathrm{mAb}$ C11C1-treated group (left) compared with the inflamed villus formation (arrows) occupying the synovial space (a) in the lgG-treated group (right). Hematoxylin and eosin stain; original magnification $\times 100$. (c) Effects of $m A b C 11 C 1$ on synovial inflammatory changes in HLA-B27 rats. Treatment with mAb C11C1 (open bars) decreased synovial proliferation (hyperplasia) $(P=$ 0.01 ), subsynovial fibrosis (fibroplasia) $(P=0.001)$, and degree of inflammation $(P<0.001)$, but not pannus formation. The total score of the control lgG1 of $9.6 \pm 1.0$ was reduced by $m A b C 11 \mathrm{C} 1$ to an inflammatory score of $5.0 \pm 1.0(P=0.009)$. Data are shown as means \pm SEM. ${ }^{*} P<0.05 ;{ }^{* \star} P<0.01 ;{ }^{* \star \star} P<0.005$. (d) Effects of mAb $\mathrm{C} 11 \mathrm{C} 1$ on cartilage and bone inflammatory changes in HLA-B27 rats. mAb C11C1 (open bars) significantly improved (decreased the Mankin score of) the cartilage organization $(P=0.01)$ and the altered chondrocyte proliferation $(P=0.008)$. The proteoglycan cartilage contents (Safranin O/Fast Green staining) were similar in both experimental groups $(P>0.05)$ and the tidemark integrity was preserved (data not shown). The total Mankin score was significantly decreased in the mAb C11C1-treated group $(P=0.02)$. Data are shown as means \pm SEM. ${ }^{*} P$ $<0.05 ;{ }^{* \star} P<0.01 ;{ }^{\star * \star} P<0.005$. 


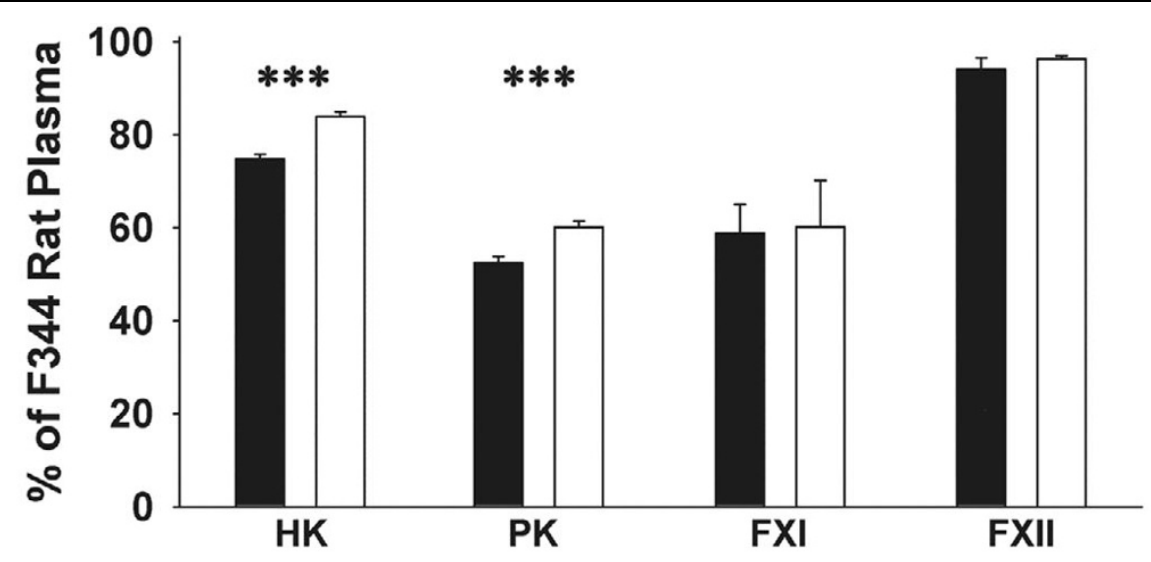

Kallikrein-kinin system (KKS) assays. Plasma KKS protein concentrations in the human leukocyte antigen B27 transgenic rats treated with control monoclonal antibody lgG (filled bars) or monoclonal antibody $\mathrm{C} 11 \mathrm{C} 1$ (open bars) at day 16 of the experimental protocol. Values were compared with a pool of normal Fischer 344 rat plasma. Both high-molecular-mass kininogen (HK) and prekallikrein (PK) were significantly decreased in the IgG1-treated group and were closer to normal in the C11C1-treated group. Both experimental groups showed decreased factor XI (FXI) with no significant differences between them. There were no significant changes between any groups in factor XII (FXII). ${ }^{* \star \star} P<0.005$.

sections showed normal architecture without any signs of inflammation or toxicity in both treated groups (results not shown).

\section{KKS activation assays}

To assess KKS system activation in this animal model of inflammation, we compared the experimental groups' results with a standard pool of normal Fischer 344 rat plasma (Fig. 4). We measured the plasma functional levels of four contact proteins. At the termination of the experiment (day 16), HK levels were reduced in both groups compared with the standard pool level. The values in the mAb C11C1-treated animals were closer to normal than those in the isotype-treated animals. HK levels were significantly lower in the isotype lgG-treated group $(74.7 \pm 1.0)$ than in the group receiving mAb C11C1 (83.9 \pm 1.1) $(P<0.001)$. PK levels were significantly decreased in the $\operatorname{lgG}$ isotype group $(52.5 \pm 1.3 \%)$ versus the mAb C11C1treated group $(60.1 \pm 1.3 \% ; P<0.005)$. Factor $\mathrm{XI}$ was similarly lower in both experimental groups but factor XII was not lower (in any group). Neither difference in factor XI or factor XII levels between the two experimental groups was significant. The results of these assays were similar to those observed in our previous studies [20], in which a decrease in HK and PK was the most consistent evidence for KKS activation.

\section{Discussion}

Therapy with $\mathrm{C} 11 \mathrm{C} 1$, a mAb that interferes with the cellular binding of $\mathrm{HK}$, evoked marked anti-inflammatory activity in both the colon and the tarsal joints of HLA-B27 transgenic rats. The onset of anti-inflammatory activity by mAb $\mathrm{C} 11 \mathrm{C} 1$ was rapid and sustained throughout the study, with the first effect seen in the intestine. The joint changes began to resolve with improvement in stool character, but it took almost 10 days for the joint swelling and erythema to reach minimal levels (as reflected in joint score values). The histological effects in the colon seemed to be more complete than those seen in the tarsal joints because only a modest effect was seen on the articular cartilage lesions, as reflected in the Mankin score. However, if one compares the colonic score results with the synovitis score results, the effect was very similar in both character and magnitude. The isotype $\operatorname{lgG}_{1}$ group $\mathrm{KKS}$ assays showed a decrease in $\mathrm{HK}$ and $\mathrm{PK}$ levels consistent with this system activation, whereas the mAb $\mathrm{C} 11 \mathrm{C} 1$-treated group showed significantly increased levels of both proteins. These observations are explained by the fact that $\mathrm{mAb} \mathrm{C} 11 \mathrm{C} 1$ inhibits the activation of $\mathrm{HK}$, thus blocking $\mathrm{KKS}$ activation and decreasing the signs of inflammation [20].

The HLA-B27 transgenic rat model has been used for several years to evaluate the activity and mechanisms of actions of anti-inflammatory molecules [22,23,30-34]. This model is very reproducible and consistent, as long as the environmental conditions remain stable. The chronic inflammation seen in these transgenic rats seems to be the result of HLA-B27 transgene expression-induced alterations in antigen processing and subsequent immune responses to the microbial environment in the lumen of the animal's gastrointestinal tract $[35,36]$. These aberrant responses lead to $\mathrm{CD} 4+\mathrm{T}$ cell activation and proinflammatory cytokine production. Broad-spectrum antibiotic therapy can produce significant remissions of the inflammatory lesions, but relapse occurs when antibiotic therapy stops [35]. If antibiotic therapy is followed by inoculation of the gut with probiotic agents such as Lactobacillus rhamnosus, relapse is prevented [36]. Lactobacilli have also been shown to be effective in treating patients with chronic pouchitis after ileal pouch-anal anastomosis for the treatment of ulcerative colitis [37]. 
In addition to antibiotics and probiotic agents, other standard anti-inflammatory agents used in the long-term treatment of IBD patients are also active in the HLA-B27 transgenic rat. Both dexamethasone and prednisolone produce dosedependent reductions in the inflammation in these animals $[38,39]$. As in patients with IBD, sulfasalazine at low doses is without effect in the HLA-B27 transgenic rat [40], but high doses do ameliorate the disease [41].

Three approaches have been used in our laboratory to show that the KKS has a major role in inflammatory arthritis and enterocolitis with the use of the PG-APS models. First, we used a specific oral reversible tight-binding active-site inhibitor of plasma kallikrein, D-Pro-Phe-boro-Arg. This specific kallikrein inhibitor attenuated acute inflammatory changes (edema, and neutrophil infiltration) and prevented arthritis and chronic systemic complications (splenomegaly, hepatomegaly, leukocytosis and the acute-phase reaction) in the PG-APS model [42]. The same plasma kallikrein inhibition modulated acute intestinal changes [28] as well as chronic granulomatous intestinal inflammation [29] similar to human Crohn's disease. Second, we showed that antagonists of BK receptor type 2 ameloriate acute arthritis [43] whereas an antagonist of BK receptor type 1 aggravated the joint inflammation [44]. We have recently shown that BK receptor antagonists can upregulate or downregulate specific cell-adhesion molecules [44]. Third, kininogen deficiency was first described in Brown Norway rats [45]. We introduced this mutation into a Lewis genetic background with five generations of backcrosses and showed that the deficiency of kininogen ameliorated acute and chronic enterocolitis [46]. Because we have previously successfully used the $\mathrm{mAb} \mathrm{C} 11 \mathrm{C} 1$ to inhibit tumor growth in a syngeneic murine model (Sainz IM, Isordia-Salas I, Pixley RA, Colman RW, unpublished work) and in a human colon carcinoma grown in a nude (immunodeficient) mouse model [47], we used this fourth approach in the present study. This antibody has recently been successfully employed in the PG-APS model in which $\mathrm{mAb}$ C11C1 inhibited inflammatory changes in joints, systemic inflammation, and activation of the kallikrein-kinin system [20]. Here we have demonstrated its efficiency in treating HLA-B27-associated inflammatory disease.

Each of the previous approaches to inhibiting the KKS to control inflammation was successful but had certain limitations. The plasma kallikrein active-site inhibitor displayed hepatic toxicity. The BK receptor antagonist had only a modest effect. Kininogen deficiency is rare in humans and is not really an applicable therapeutic modality. However, we were encouraged by the success of mAb C11C1 in the PG-APS model in the prevention of systemic and joint inflammation [20] and the lack of obvious side effects. The fact that antibodies against other inflammatory agonists have been used in the treatment of human IBD, arthritis and cancer make its use attractive. Until this study, mAb $\mathrm{C} 11 \mathrm{C} 1 \mathrm{had}$ been used in a preventive mode. The HLA-B27 transgenic rat model permitted the rapid treat- ment of an established disease model. On the basis of these results, we suggest that $\mathrm{mAb} \mathrm{C} 11 \mathrm{C} 1$ might be a candidate for a therapeutic agent in human inflammatory disease.

\section{Conclusion}

We have assessed a transgenic rat model in which the human gene encoding HLA-B27 has been overexpressed. These rats developed T cell-mediated, spontaneous arthritis resembling reactive or inflammatory arthritis. We were able to successfully treat an established disease with an antibody against kininogen without inducing side effects or toxicity in either the rat or the mouse model of the disease.

\section{Competing interests}

The author(s) declare that they have no competing interests.

\section{Authors' contributions}

JCK planned and supervised the entire animal protocol. $\mathrm{He}$ also participated in the statistical analysis and writing of the clinical results section and in the editing of the manuscript. IMS assessed the potential toxic effects of the treatment on kidney, lungs and liver. She also prepared the final version of all figures and collaborated in the statistical analysis, editing, and typing of the manuscript. IIS performed the KKS assays and, together with RAP, purified the antibody. RAP also participated in the statistical analysis, editing of the manuscript, and preparation of the KKS figure. YL performed the animal protocol and collected the data. LMA participated in the planning and execution of the animal project. RWC planned and initiated the entire product, wrote the introduction and discussion portions of the manuscript, and was responsible for final editing. All authors read and approved the final manuscript.

\section{Acknowledgements}

We thank Virginia Sheaffer for careful manuscript preparation, and Dr Ricardo Espinola for his technical support in this study. Grant support was received from the National Institutes of Health (grants R01 CA83121 and R01 AR051713) and the Broad Medical Research Program (IBD-0080R).

\section{References}

1. Taurog JD, Richardson JA, Croft JT, Simmons WA, Zhou M, Fernandez-Sueiro JL, Balish E, Hammer RE: The germfree state prevents development of gut and joint inflammatory disease in HLA-B27 transgenic rats. J Exp Med 1994, 180:2359-2364.

2. Hammer RE, Maika SD, Richardson JA, Tang JP, Taurog JD: Spontaneous inflammatory disease in 7 transgenic rats expressing HLA-B27 and human beta $2 \mathrm{~m}$ : an animal model of HLA-B27associated human disorders. Cell 1990, 63:1099-1112.

3. Sartor RB, Rath HC, Lichtman SN, van Tol EA: Animal models of intestinal and joint inflammation. Baillieres Clin Rheumatol 1996, 10:55-76.

4. Breban M: HLA-B27 transgenic rats model. Ann Med Interne (Paris) 1998, 149:139-141.

5. Joseph K, Shibayama Y, Ghebrehiwet B, Kaplan AP: Factor XIIdependent contact activation on endothelial cells and binding proteins gC1qR and cytokeratin 1. Thromb Haemost 2001, 85:119-124.

6. Shariat-Madar Z, Mahdi F, Schmaier AH: Identification and characterization of prolylcarboxypeptidase as an endothelial cell prekallikrein activator. J Biol Chem 2002, 277:17962-17969. 
7. Chavakis T, Santoso S, Clemetson KJ, Sachs UJ, Isordia-Salas I, Pixley RA, Nawroth PP, Colman RW, Preissner KT: High molecular weight kininogen regulates platelet-leukocyte interactions by bridging Mac-1 and glycoprotein Ib. J Biol Chem 2003, 278:45375-45381.

8. Colman RW: Plasma and tissue kallikrein in arthritis and inflammatory bowel disease. Immunopharmacology 1999, 43:103-108.

9. Schapira M, Despland E, Scott CF, Boxer LA, Colman RW: Purified human plasma kallikrein aggregates human blood neutrophils. J Clin Invest 1982, 69:1199-1202.

10. Wachtfogel YT, Kucich U, James HL, Scott CF, Schapira M, Zimmerman $\mathrm{M}$, Cohen $\mathrm{AB}$, Colman RW: Human plasma kallikrein releases neutrophil elastase during blood coagulation. J Clin Invest 1983, 72:1672-1677.

11. Colman RW, Pixley RA, Sainz I, Song JS, Isordia-Salas I, Muhamed SN, Powell JA Jr, Mousa SA: Inhibition of angiogenesis by antibody blocking the action of proangiogenic high-molecularweight kininogen. J Thromb Haemost 2003, 1:164-170.

12. Regoli $D$, Barabe J: Pharmacology of bradykinin and related kinins. Pharmacol Rev 1980, 32:1-46.

13. Liu B, Li F, Isordia-Salas I, Bradford HN, Colman RW, Pixley RA, Sartor RB: Cleavage products of kininogen variably induce proinflammatory cytokines by Fischer rat splenocytes [Abstract]. Gastroenterology 2004, 126:A573.

14. Khan MM, Bradford HN, Isordia-Salas I, Espinola R, Colman RW: High molecular weight kininogen fragments stimulate the secretion of interleukin $1 \mathrm{~b}$ through urokinase-type plasminogen activator receptor (UPAR) and CD11b/CD18 (Mac-1) in human blood mononuclear cells [abstract]. Blood 2004, 104:36b.

15. DeLa Cadena RA, Laskin KJ, Pixley RA, Sartor RB, Schwab JH, Back N, Bedi GS, Fisher RS, Colman RW: Role of kallikreinkinin system in pathogenesis of bacterial cell wall-induced inflammation. Am J Physiol 1991, 260:G213-G219.

16. Sartor RB, DeLa Cadena RA, Green KD, Stadnicki A, Davis SW, Schwab JH, Adam AA, Raymond P, Colman RW: Selective kallikrein-kinin system activation in inbred rats differentially susceptible to granulomatous enterocolitis. Gastroenterology 1996, 110:1467-1481.

17. Isordia-Salas I, Pixley RA, Parekh H, Kunapuli SP, Li F, Stadnicki A, Lin Y, Sartor RB, Colman RW: The mutation Ser511Asn leads to $\mathrm{N}$-glycosylation and increases the cleavage of high molecular weight kininogen in rats genetically susceptible to inflammation. Blood 2003, 102:2835-2842.

18. Blais C Jr, Couture R, Drapeau G, Colman RW, Adam AA: Involvement of endogenous kinins in the pathogenesis of peptidoglycan-induced arthritis in the Lewis rat. Arthritis Rheum 1997, 40:1327-1333.

19. Stadnicki A, Sartor RB, Janardham R, Stadnicka I, Adam A, Blais $C$, Colman RW: Kallikrein-kininogen system activation and bradykinin (B2) receptors in indomethacin-induced enterocolitis in genetically susceptible Lewis rats. Gut 1998, 43:365-374.

20. Espinola RG, Uknis A, Sainz IM, Isordia-Salas I, Pixley RA, DeLa Cadena R, Long W, Agelan A, Gaughan J, Adam A, et al.: A monoclonal antibody to high molecular weight knininogen is therapeutic in a rodent model of reactive arthritis. $A m$ J Pathol 2004, 165:969-976.

21. Keith JC Jr, Albert L, Sonis ST, Pfeiffer CJ, Schaub RG: IL-11, a pleiotropic cytokine: exciting new effects of IL-11 on gastrointestinal mucosal biology. Stem Cells 1994, 12:79-89.

22. Harris HA, Albert LM, Leathurby Y, Malamas MS, Mewshaw RE, Miller CP, Kharode YP, Marzolf J, Komm BS, Winneker RC, et al.: Evaluation of an estrogen receptor-beta agonist in animal models of human disease. Endocrinology 2003, 144:4241-4249.

23. Peterson RL, Wang L, Albert L, Keith JC Jr, Dorner AJ: Molecular effects of recombinant human interleukin-11 in the HLA-B27 rat model of inflammatory bowel disease. Lab Invest 1998, 78:1503-1512.

24. Boughton-Smith NK, Wallace JL, Morris GP, Whittle BJ: The effect of anti-inflammatory drugs on eicosanoid formation in a chronic model of inflammatory bowel disease in the rat. $\mathrm{Br} J$ Pharmacol 1988, 94:65-72.
25. Poole AR, Coombs RR: Rheumatoid-like joint lesions in rabbits injected intravenously with bovine serum. Int Arch Allergy Appl Immunol 1977, 54:97-113.

26. Mankin HJ, Dorfman H, Lippiello L, Zarins A: Biochemical and metabolic abnormalities in articular cartilage from osteoarthritic human hips. II. Correlation of morphology with biochemical and metabolic data. J Bone Joint Surg Am 1971, 53:523-537.

27. Scott CF, Silver LD, Purdon AD, Colman RW: Cleavage of human high molecular weight kininogen by factor Xla in vitro. Effect on structure and function. J Biol Chem 1985, 260:10856-10863.

28. Stadnicki A, DeLa Cadena RA, Sartor RB, Bender D, Kettner CA, Rath HC, Adam A, Colman RW: Selective plasma kallikrein inhibitor attenuates acute intestinal inflammation in Lewis rat. Dig Dis Sci 1996, 41:912-920.

29. Stadnicki A, Sartor RB, Janardham R, Majluf-Cruz A, Kettner $C$, Adam AA, Colman RW: Specific inhibition of plasma kallikrein modulates chronic granulomatous intestinal and systemic inflammation in genetically susceptible rats. FASEB J 1998, 12:325-333.

30. Harnish DC, Albert LM, Leathurby Y, Eckert AM, Ciarletta A, Kasaian M, Keith JC Jr: Beneficial effects of estrogen treatment in the HLA-B27 transgenic rat model of inflammatory bowel disease. Am J Physiol Gastrointest Liver Physiol 2004, 286:G118-G125.

31. Peterson RL, Wang L, Albert L, Marchese E, Erickson J, Wong A Mounts WM, Hayes L, Bouchard P, Keith J, et al:: Pharmacogenomic analysis of rhIL-11 treatment in the HLA-B27 rat model of inflammatory bowel disease. Pharmacogenomics J 2002, 2:383-399.

32. Greenwood-Van Meerveld B, Venkova K, Keith JC Jr: Recombinant human interleukin-11 restores smooth muscle function in the jejunum and colon of human leukocyte antigen-B27 rats with intestinal inflammation. J Pharmacol Exp Ther 2001, 299:58-66.

33. Albert LM, Patel U, Ferranti TJ, Ahmed A, Schaub RG, Keith JCJ: Soluble recombinant human $p$-selectin glycoprotein ligand-1 (sPSGL-1) decreases intestinal lesions in HLA-B27 transgenic rats and in acetic acid induced colitis in Sprague-Dawley rats [Abstract]. Am Gastroenterology Soc 1998, 114:A918.

34. Chadwick CC, Chippari S, Matelan E, Borges-Marcucci L, Eckert AM, Keith JC Jr, Albert LM, Leathurby Y, Harris HA, Bhat RA, et al.: Identification of pathway-selective estrogen receptor ligands that inhibit NF-KB transcriptional activity. PNAS 2005, 102:2543-2548.

35. Dieleman LA, Hoentjen F, Qian BF, Sprengers D, Tjwa E, Torres MF, Torrice CD, Sartor RB, Tonkonogy SL: Reduced ratio of protective versus proinflammatory cytokine responses to commensal bacteria in HLA-B27 transgenic rats. Clin Exp Immunol 2004, 136:30-39.

36. Dieleman LA, Goerres MS, Arends A, Sprengers D, Torrice C, Hoentjen F, Grenther WB, Sartor RB: Lactobacillus GG prevents recurrence of colitis in HLA-B27 transgenic rats after antibiotic treatment. Gut 2003, 52:370-376.

37. Gionchetti $P$, Rizzello $F$, Venturi $A$, Brigidi $P$, Matteuzzi $D$, Bazzocchi G, Poggioli G, Miglioli M, Campieri M: Oral bacteriotherapy as maintenance treatment in patients with chronic pouchitis: a double-blind, placebo-controlled trial. Gastroenterology 2000, 119:305-309.

38. Kim YS, Son M, Ko Jl, Cho H, Yoo M, Kim WB, Song IS, Kim CY: Effect of DA-6034, a derivative of flavonoid, on experimental animal models of inflammatory bowel disease. Arch Pharm Res 1999, 22:354-360.

39. Blanchard HS, Dernis-Labous E, Lamarque D, Nhieu JT, Szepes Z, Flejou JF, Wollman E, Whittle BJ, Breban M: Inducible nitric oxide synthase attenuates chronic colitis in human histocompatibility antigen HLA-B27/human beta2 microglobulin transgenic rats. Eur Cytokine Netw 2001, 12:111-118.

40. Aiko S, Fuseler J, Grisham MB: Effects of nitric oxide synthase inhibition or sulfasalazine on the spontaneous colitis observed in HLA-B27 transgenic rats. J Pharmacol Exp Ther 1998, 284:722-727.

41. Kerr SW, Wolyniec WW, Filipovic Z, Nodop SG, Braza F, Winquist RJ, Noonan TC: Repeated measurement of intestinal permeability as an assessment of colitis severity in HLA-B27 transgenic rats. J Pharmacol Exp Ther 1999, 291:903-910. 
42. DeLa Cadena RA, Stadnicki A, Uknis AB, Sartor RB, Kettner CA, Adam A, Colman RW: Inhibition of plasma kallikrein prevents peptidoglycan-induced arthritis in the Lewis rat. FASEB $J$ 1995, 9:446-452.

43. Uknis AB, DeLa Cadena RA, Janardham R, Sartor RB, Whalley ET, Colman RW: Bradykinin receptor antagonists type 2 attenuate the inflammatory changes in peptidoglycan-induced acute arthritis in the Lewis rat. Inflamm Res 2001, 50:149-155.

44. Sainz IM, Uknis AB, Isordia-Salas I, Dela Cadena RA, Pixley RA, Colman RW: Interactions between bradykinin (BK) and cell adhesion molecule (CAM) expression in peptidoglycanpolysaccharide (PG-PS)-induced arthritis. FASEB J 2004, 18:887-889.

45. Hayashi I, Hoshiko S, Makabe O, Oh-ishi S: A point mutation of alanine 163 to threonine is responsible for the defective secretion of high molecular weight kininogen by the liver of brown Norway Katholiek rats. J Biol Chem 1993, 268:17219-17224.

46. Isordia-Salas I, Pixley RA, Li F, Sainz I, Sartor RB, Adam A, Colman RW: Kininogen deficiency modulates chronic intestinal inflammation in genetically susceptible rats. Am J Physiol Gastrointest Liver Physio/ 2002, 283:G180-G186.

47. Song JS, Sainz I, Cosenza SC, Isordia-Salas I, Bior AD, Bradford HN, Guo YL, Pixley RA, Reddy EP, Colman RW: Inhibition of tumor angiogenesis in vivo by monoclonal antibody targeted to domain $\mathbf{5}$ of high molecular weight kininogen. Blood 2004, 104:2065-2072. 